\title{
Using Pyramid Discussions in the Task-based Classroom to Extend Student Talking Time
}

\author{
Mehran Esfandiari ${ }^{1, *}$ \& Paul Knight ${ }^{1}$ \\ ${ }^{1}$ School of Education, The University of Nottingham, Nottingham, UK \\ *Corresponding author: School of Education, The University of Nottingham, Nottingham, Nottinghamshire, NG8 \\ 1BB, UK. Tel: 44-741-180-5580. E-mail: ttxme19@nottingham.ac.uk
}

Received: June 15, 2013

Accepted: July 2, $2013 \quad$ Online Published: August 2, 2013

doi:10.5430/wjel.v3n3p20

URL: http://dx.doi.org/10.5430/wjel.v3n3p20

\begin{abstract}
Since the emergence of Communicative Language Teaching (CLT), the belief that languages are acquired through communication has been a central tenet of language teaching methodology. This belief has continued to be central to the development of task-based approaches to language teaching that have built upon the ideas of CLT, its models of language learning and ideas of learner-centeredness. This paper considers strategies to maximize student communication within a task-based classroom environment and presents a case study into the use of pyramid discussions within a task-based classroom to maximize student communication. Working within Jane Willis' well-known task framework, this study shows how pyramid discussions can significantly help to increase student communication opportunities when compared to more traditional teacher-fronted approaches.
\end{abstract}

Keywords: task-based learning; CLT; student talking time; interaction; communicative classrooms; discussions

\section{Introduction}

In order for teachers to successfully teach in the classroom, talking to students is natural and inevitable. However, taking into account the restricted amount of time that second language learners have for oral language practice, the extent to which teacher talk can dominate language lessons is an important issue. It is usually the case that the main place where foreign language learners are exposed to the target language is in the classroom. This is particularly true in English as a Foreign Language (EFL) classes because students are not benefitting from the chance to live in an English-speaking environment. Therefore, striking the right balance between Teacher Talking Time (TTT) and Student Talking Time (STT) in order to maximize opportunities for student communication is an important consideration.

In the past, when there was a tradition of 'chalk and talk', a great deal of TTT was encouraged because the teacher was the dominating authority in class, and was expected to transmit the knowledge to students (Scrivener, 2005). At that time, the focus was on the language itself rather than on the way it is used. However, with the shift towards communicative language teaching, student-centered classes are encouraged so that learners can acquire the language as the result of communication, interaction, and negotiation of meaning (Lightbrown \& Spada, 1999). For the last 30 years, trainee teachers have been told that inexperienced teachers tend to fill silences by unnecessary talking, whereas a good lesson is the one which maximizes learners' opportunities to engage in communicative tasks.

The aim of this article is to present the results of a case study into the use of pyramid discussions within a task-based classroom following the task cycle recommended by Willis (1996) which highlights the value of activities which maximize student talking time. In doing so, it suggests that such activities by maximizing student talking and interaction are a useful tool in creating the optimum conditions for language learning.

\section{The Importance of STT in the Communicative Classroom}

In traditional pre-communicative learning environments, the teacher was expected to take a central role and transmit his language knowledge to the students. The phrase 'jug and mug' can be used to describe this traditional way of teaching as the teacher's knowledge was supposed to be poured into the minds of students (Scrivener, 2005). Thus, 
traditional approaches encouraged a significant amount of TTT. However, the development of communicative language teaching radically changed the world of English language teaching by introducing a methodology centered on promoting communication in the classroom and raising student involvement in the learning process (Howatt \& Widdowson, 2004). Within this new paradigm, excessive amounts of TTT were seen to be at the expense of opportunities to promote student interaction and therefore learning. Therefore, teachers are recommended to minimize TTT while maximizing STT.

One of the key elements of modern approaches to language teaching is that people learn things by doing and experiencing them. If the teacher maintains a dominant role in the classroom, learners may not be encouraged to take responsibility for their own learning and their role may be restricted to that of being simply respondents to teacher input. It is clearly apparent that TTT and STT have an inverse relationship with each other. Since student interaction leads to language learning, Richards (2006) suggests the following strategies so that teachers will be able to reduce their talking time and increase opportunities for learner talk in the classroom:

1. The use of elicitation rather than explanation.

2. Organizing activities as pair or group work.

3. Using body language, mime, gestures, and facial expressions rather than words.

4. Getting students to give feedback on tasks to each other rather than to the teacher.

The case study presented in this paper focuses on realizing the second and fourth of these strategies.

\section{Task-based learning (TBL)}

Building on the claim that language is acquired through communication, a 'strong' version of CLT was developing that entailed 'using English to learn it' (Howatt \& Widdowson, 2004). Simply stated, this version asserts that learners discover the system of a language as they learn how to communicate in that language. In order for learners to build up communicative competence, the strong version of CLT encourages teachers to move beyond presenting structural rules of the language to creating opportunities for students to meaningfully practice communication skills. Since the task-based approach draws on several principles that have formed part of the communicative language teaching movement from the 1980s, it is presented by its proponents as not only a logical development of CLT, but also as its strong version.

TBL lays great emphasis on interaction and practical purposes for which language must be used, not on the language itself (Brown, 2001). Its main aim is to supply learners with a natural context for language use in the form of a task, which calls for students to interact in order to achieve an outcome. Such interaction paves the way for language acquisition as learners are required to express their own meaning and understand each other (Larsen-Freeman, 2000). That is to say, the language needs to be used by students in unrehearsed contexts not only productively, but also receptively by attempting to communicate using their own linguistic and non-linguistic resources.

It is a central tenet of TBL that languages are learned through interaction and negotiation (Richards, 2006). Walsh (2006) believes that as the result of meaningful and purposeful interaction with others, there is no alternative for learners but to modify their speech so that understanding takes place. Long (1996: 451-2) points out that "especially negotiation work that triggers interactional adjustments by the native speaker or more competent interlocutor, facilitates acquisition because it connects input, internal learner capacities, particularly selective attention, and output in productive ways". With its main focus on fluency rather than accuracy, TBL is based on the assumption that languages are learned best through authentic acts of communication, interaction, and negotiation of meaning (Skehan, 1998; Richards \& Rodgers, 2001; Ellis, 2003). Thus, plenty of student talking time is encouraged.

To encourage the use of tasks in the language classroom, a TBL framework was proposed by Jane Willis in 1996. It is comprised of three phases, pre-task, the task cycle, and the language focus phase. It is important to note that similar frameworks have been subsequently proposed by other proponents of TBL, notably Nunan (2004). The 'task cycle' in Willis' framework is the stage where learners can benefit from a holistic experience of language in use. It provides them with an opportunity to not only use the language they already know, but also to experiment with new language while being monitored by the teacher. In the authors' experience, pyramid discussions are a positive addition to this cycle, as this paper seeks to demonstrate.

The task cycle this paper has used is the one that was established by Willis as the second part of her framework for TBL. It consists of three steps as follows: 
1 Task: In the first step, learners work together either in pairs or small groups, and use their knowledge of the language to achieve the goals of the task. Activities are normally carried out by students in small groups because negotiation of meaning can result when learners are involved in group work and freely interact with each other (Larsen-Freeman, 2000; Bruton, 2002). Negotiation of meaning can result in learners' interlanguage being brought into line with the target language (Walsh, 2006).

2 Planning: As the central part of the task cycle, the main aim of the planning stage is to help learners plan their reports in an effective way. It also doubles as a tool for maximizing learning opportunities. Learners prepare themselves to report to the class how they have accomplished the task and what decisions or discoveries they have made. In addition, they rehearse oral reports or draft a written version for the class to read. On the other hand, the teacher takes the role of a language adviser and makes sure that the purpose of the report is clear.

3 Report: The reporting stage rounds the task cycle off by providing students a linguistically demanding opportunity to communicate their decisions/findings, either orally or in written form. At this stage, the teacher not only acts as a chairperson by choosing who will speak or read the written reports, but also may give brief feedback on content and form.

The interesting thing about pyramid discussions is that depending upon the number of learners, this cycle can be repeated several times. This is because in most stages of a pyramid discussion, students are required to work in pairs or groups and plan their reports by comparing ideas, convincing each other, and finally reaching an agreement before they meet others to form larger groups and repeat the process.

\section{Context setting}

The study was conducted in the Centre for English Language Education (CELE), at the University of Nottingham, located in the UK. There was a group of 16 Chinese students studying on a 10-week English for Academic Purposes (EAP) course in order to gain entry to postgraduate degree programs. In terms of proficiency in English, all of them were at approximately IELTS 6. They had a one-hour session of fluency activities once a week as part of the speaking component of their EAP course. The main aim of these lessons was to improve their seminar skills. For the purposes of this study, a one-hour session was divided in half. The first half an hour was allocated to the fluency activities from their course book, while the second half an hour of the lesson was allocated to the pyramid discussion activity outlined below.

\section{Method}

\subsection{Pyramid Discussions}

Student discussions are a common activity in the language classroom, and depending upon the context and the issue being discussed, the teacher can encourage either competition or cooperation between the students. Discussions are relatively easy to organize (Richards, 2006), and are a form of communicative activity that can significantly increase student talking time in the communicative classroom (Scrivener, 2005).

In a pyramid discussion, students first undertake a speaking task in small groups where they have to agree on some certain items. Then, they join another group and have to reach an agreement again. This gives students time to practice speaking in smaller groups before facing the whole class. As a less controlled fluency activity, they can help learners to practice a broad range of language that they have both been formally taught in the classroom or acquired from elsewhere. They help students build up confidence by rehearsing and repeating arguments that they have already used on others. Learners form progressively larger groups by coming to an agreement at each stage until finally the whole class is involved in one discussion. The idea behind a pyramid discussion is that learners should come to an agreement when they reach the top of the pyramid (see Figure 1). 


\section{TPTITITITITIT

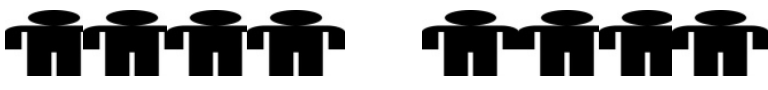

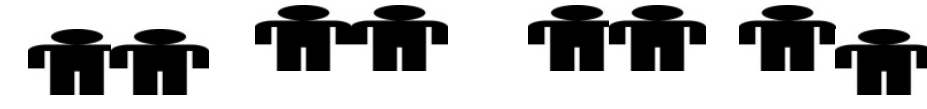

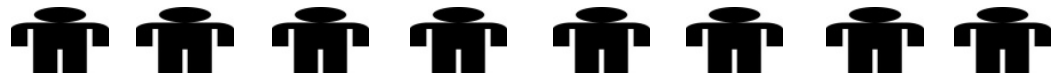

Figure 1: Framework of Pyramid Discussions

It should also be mentioned that as an organizational technique, pyramid discussions work particularly well with item-selection tasks, where students are required to agree on a specific number of items presented from a larger group for their discussion. Therefore, it is important to prepare a challenging list of topic-related items in order to encourage a high level of interaction, conversation, and language use. Reaching decisions on which items to select should not be too straightforward and require genuine discussion of views, for example, an activity that requires learners to select 10 items from a list of 20 to pack for a holiday should contain 20 items that could all realistically be chosen.

\subsection{The Lesson}

In the authors' experience, the first and most important part of any pyramid discussion is to prepare a task that matches the definition offered by Willis. However, it should also be based on a topic of general interest (Lightbrown \& Spada, 1999). The topic of "ONE WEEK ON A DESERT ISLAND” was chosen for this lesson, and a handout was prepared to show a list of 16 items as follows:

Table 1: List of Items

\begin{tabular}{llllclcl}
\hline 1 & Compass & 5 & Shovel & 9 & Rope & 13 & Axe \\
2 & Bow and arrow & 6 & Tin opener & 10 & Backpack & 14 & Tent \\
3 & Matches & 7 & Knife & 11 & Can of fish & 15 & Water canteen \\
4 & Sleeping bag & 8 & Hand saw & 12 & Hammer & 16 & Blanket \\
\hline
\end{tabular}

However, learners were expected to reach an agreement as the whole class on only eight items. The list was made as challenging as possible by opting for only those items that seemed to be really necessary so that learners had to use a lot of language in order to convince each other and reach a final agreement.

1 At the beginning of the pyramid discussion lesson, TTT was reduced by using elicitation to introduce the topic to be discussed (Richards, 2006). The topic was written on the board, but in the following way:

$$
\text { "O ... E W ..... K ON A D ... S .. RT ... ... AND" }
$$

Then, students were encouraged to help the teacher fill in the gaps until the topic was complete. Next, the task was explained, and handouts distributed.

2 Then, learners were given some time to work on their own and decide on their own eight items. They were also told to consider how they would explain their choices.

3 From this point onwards, it was time to put pair and group work into practice. Thus, learners were asked to pause and they were given some more time to work in pairs by comparing their lists and reaching an agreement on their items. At the same time, the teacher was going round the class to monitor the activity for future follow-up (Willis, 1996).

4 It is important to note that small groups are seedbeds for a wide variety of ideas. Therefore, at this stage, once again students were asked to pause, and they were given some more time to agree on their items by comparing their lists in small groups. The teacher took the same role as in the previous stage, however, he did listen out for errors learners were making and wrote them down because this was a fluency activity, and it was not a good idea to interrupt learners in the middle (Howatt \& Widdowson, 2004). 
5 At this stage, it was time to divide learners into half or just two large groups, and again give them some more time to compare their lists and discuss reasons before coming to an agreement on eight items. The teacher was supposed to stick to the same role as in the previous stage.

6 Finally, in order for the teacher and learners to be managers of learning, it was time to give control of the class to learners. Therefore, one learner was appointed as the leader of the group who had to take responsibility for making sure that the whole class was in agreement on only eight items. The leader was asked to come to the front of the class and make the final list of them, which the whole class had to agree about, on the board. On completion of this stage, learners' attention was drawn to the language used while the activity was in progress. However, it is important to note that it was done without attributing any linguistic errors to a particular individual. The teacher opted for peer correction through elicitation, and teacher correction was only encouraged as the last resort.

\section{Discussion of the Results}

As mentioned earlier, the first half an hour of this one-hour lesson was allocated to the activities in their course book. These were information-transfer activities where students were required to work in pairs and use the information provided to provide answers to a number of questions regarding going on a trip. For these activities, students worked in pairs only and then selected pairs reported back to the whole class. The tutor then provided feedback on the responses given. This cycle was repeated three times as different aspects of planning a trip were considered. This typically meant that students spent a total of 9 minutes working in pairs discussing the answers (see Table 2).

Table 2: Amounts of STT at Different Stages of the First Half of the Lesson

\begin{tabular}{lcc}
\hline & Time Limit & Amount of STT \\
\hline Cycle 1 & $10 \mathrm{~min}$. & $3 \mathrm{~min}$. \\
Cycle 2 & $10 \mathrm{~min}$. & $3 \mathrm{~min}$. \\
Cycle 3 & $10 \mathrm{~min}$. & $3 \mathrm{~min}$. \\
Total & $30 \mathrm{~min}$. & $9 \mathrm{~min}$. \\
\hline
\end{tabular}

However, in the second half of the lesson, where there was a pyramid discussion, a big difference was observed. This was mainly because the whole class was involved in the repeating task cycle, as a result of which there was a great deal of STT, which involved everyone in the class. Therefore, the amount of time the average student was given to talk climbed dramatically. Figure 2 shows the amounts of STT at different stages of the pyramid discussion lesson.

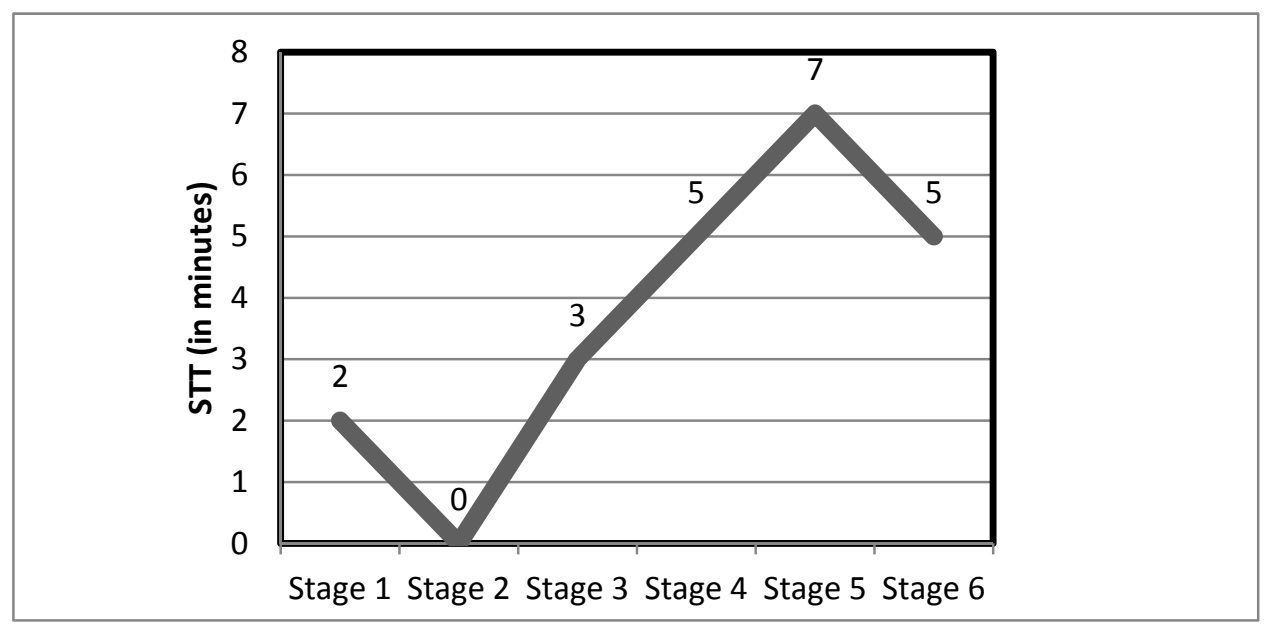

Figure 2: Amounts of STT at Different Stages of the Pyramid Discussion Lesson

With the exception of Stage 2 of the pyramid discussion, where students were involved in individual planning, the amount of STT rose significantly. By making a comparison between the total STT in the first half of the lesson, 9 minutes, and its corresponding figure for the pyramid discussion lesson, an additional 13 minutes of STT can be taken into account, making it totally 22 minutes as the total STT for the pyramid discussion part of the lesson. Figure 3 shows the total amounts of STT for both of the lessons. 


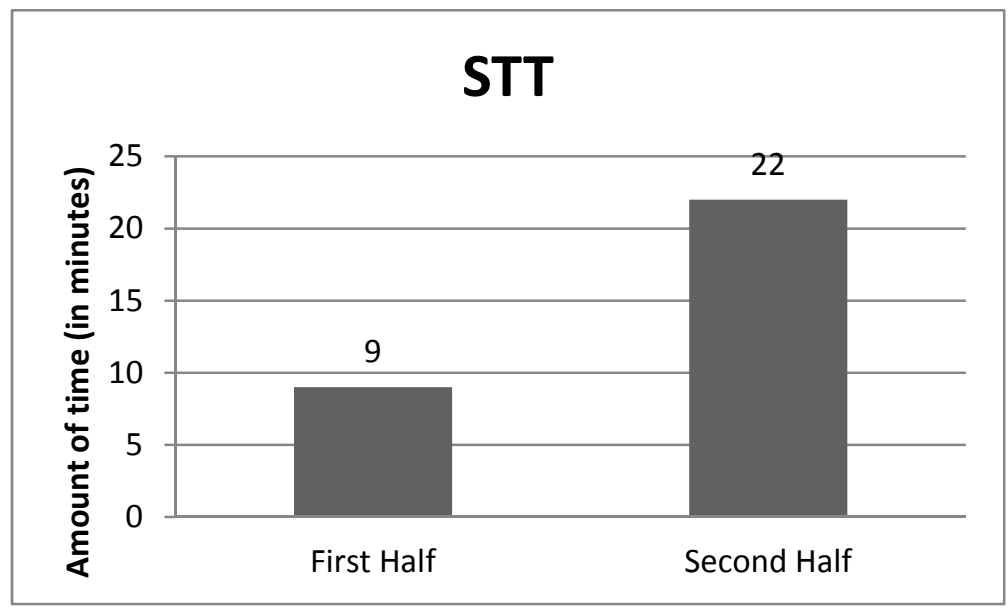

Figure 3: Total Amounts of STT

Summing up the results, it is obvious that the students benefitted from a significantly larger amount of talking time in the pyramid discussion half of the lesson. In fact, an over two fold increase can be seen in the amount of STT, which is largely due to every single student being involved in the repeated task cycle.

\section{Conclusion}

With the shift from traditional towards more communicative approaches to language learning and teaching, teachers are recommended to maximize opportunities for their learners to interact with each other and learn the target language through communication. Within the TBL paradigm, this is thought to create the optimal SLA conditions for language learning to arise. Therefore, teachers need to identify those activities which maximize student communication. This study suggests that pyramid discussions used within a TBL task cycle are one way to achieve this. They encourage learners to reach agreement on a restricted number of items and through the process of smaller groups merging into larger ones until the whole class is involved in one discussion maximize opportunities for student interaction. In fact, due to the particular structure of pyramid discussions, the task cycle is repeated several times, which leads to a significantly increased student talking time and results in learners having increased opportunities to acquire language through negotiation and interaction.

\section{References}

Brown, H.D. (2001). Teaching by Principles - An Interactive Approach to Language Pedagogy (Second edition). London: Pearson Education.

Bruton, A. (2002). From tasking purposes to purposing tasks. ELT Journal, 56(3), 280-295. http://dx.doi.org/10.1093/elt/56.3.280

Ellis, R. (2003). Task-based language learning and teaching. Oxford: Oxford University Press.

Howatt, A. P. R., \& Widdowson, H.G. (2004). A History of English Language Teaching. Oxford: Oxford University Press.

Larsen-Freeman, D. (2000). Techniques and principles in language teaching. New Work: Oxford University Press.

Lightbrown, P.M., \& Spada, N. (1999). How Languages are Learned. Oxford: Oxford University Press.

Long, M. H. (1996). The role of the linguistic environment in second language acquisition. Handbook of Second language Acquisition. W. Ritchie and T. Bhatia. New York, Academic Press: 413-468.

Nunan, D. (2004). Task-Based Language Teaching. Cambridge: Cambridge University Press. http://dx.doi.org/10.1017/CBO9780511667336

Richards, J.C. (2006). Communicative language teaching today. New York: Cambridge University Press.

Richards, J.C., \& Rodgers, T.S. (2001). Approaches and methods in language teaching. Cambridge: Cambridge University Press. http://dx.doi.org/10.1017/CBO9780511667305 
Skehan, P. (1998). A cognitive approach to language learning. Oxford: Oxford University Press.

Scrivener, J. (2005). Learning Teaching (Second edition). Oxford: Macmillan Education.

Walsh, S. (2006). Investigating Classroom Discourse. Abingdon: Routledge.

Willis, J. (1996). A framework for task-based learning. Harlow: Longman. 